\title{
Contribution of parental blood pressures to association between low birth weight and adult high blood pressure: cross sectional study
}

\author{
Brian R Walker, Alex McConnachie, Joseph P Noon, David J Webb, Graham C M Watt
}

Department of

Medicine,

University of

Edinburgh, Western

General Hospital,

Edinburgh

EH4 2XU

Brian R Walker,

senior clinical

research fellow

Joseph P Noon,

research nurse

David J Webb,

professor

Department of

General Practice

University of

Glasgow, Woodside

Health Centre

Glasgow G20 7LR

Alex McConnachie,

statistician

Graham C M Watt,

professor

Correspondence to:

Dr Walker

B.Walker@ed.ac.uk

BMJ 1998;316:834-7

\begin{abstract}
Objective: To examine the possibility that low birth weight is a feature of the inherited predisposition to high blood pressure.

Design: Cross sectional study.

Setting: Primary care medical centre in Edinburgh. Subjects: One offspring of 452 families (231 men and 221 women aged 16-26 years) in whom blood pressure, weight, and height were measured in 1986 and whose parents had blood pressure measured in 1979. Birth weights were obtained from case records (270 offspring) or by questionnaires sent to the mothers (182 offspring).
\end{abstract}

Main outcome measures: Birth weight and adult systolic blood pressure in offspring in relation to parental blood pressure.

Results: If parental blood pressures were not considered, a $1 \mathrm{~kg}$ decrease in birth weight was associated with a $2.24 \mathrm{~mm} \mathrm{Hg}$ increase in systolic blood pressure of offspring $(\mathrm{P}=0.06)$ after correction for current weight and sex. However, parental blood pressures correlated positively with blood pressure of offspring, and higher maternal blood pressure was associated with lower birth weight $(-3.03 \mathrm{~g} / \mathrm{mm} \mathrm{Hg}$, $\mathrm{P}<0.01)$. After correction for parental blood pressures, a $1 \mathrm{~kg}$ decrease in birth weight was associated with only a $1.71 \mathrm{~mm} \mathrm{Hg}$ increase in the systolic blood pressure of the offspring $(\mathrm{P}=0.15)$. Conclusions: Low birth weight is a feature of the inherited predisposition to hypertension, perhaps because it is associated with higher maternal blood pressure during pregnancy. Parental blood pressure may be an important confounding factor in the relation between low birth weight and subsequent hypertension.

\section{Introduction}

During the past decade a series of epidemiological studies in several countries has documented that babies of low birth weight have higher blood pressure as children and adults. ${ }^{1-3}$ These relations are maintained after correction for gestational age at birth or other influences on blood pressure in later life, including obesity, socioeconomic group, and alcohol consumption. The association between low birth weight and subsequent hypertension may be explained by inadequate fetal nutrition during pregnancy, resulting either from inadequate maternal nutrition or placental dysfunction. ${ }^{4}$ Fetal adaptations to undernutrition are thought to programme permanent changes in factors that influence blood pressure in later life, including cortisol, growth factors, and insulin. ${ }^{4}$ This model is supported by experiments in animals, in which manipulations in utero, including maternal undernutrition $^{5}$ and treatment with glucocorticoids, ${ }^{6}$ result in lower birth weight, raised blood pressure, and hormonal abnormalities in the adult offspring.

Both blood pressure ${ }^{7}$ and birth weight ${ }^{8}$ are influenced by hereditary factors, so there may be a familial association between low birth weight and hypertension which does not depend on programming of raised blood pressure. Therefore, assessment of the parental background of people with low birth weight and subsequent hypertension is important. Studies which included information about the participants' mothers have shown that maternal smoking, socioeconomic group, and anaemia did not explain the observed relations between low birth weight and subsequent high blood pressure. ${ }^{9-11}$ Maternal blood pressure has been assessed during pregnancy, when higher pressures were associated with lower birth weight ${ }^{12-14}$ and higher blood pressure in the offspring. ${ }^{13}{ }^{15-17}$ Only one study has measured maternal blood pressure outside pregnancy, and this showed that higher blood pressure in 4 year old children was associated with both lower birth weight and higher maternal blood pressure. $^{11}$ To our knowledge, no study has taken account of any paternal factor other than socioeconomic group. We examined a population of young adults in whom blood pressures have been measured in both parents and sought to establish the contribution of parental blood pressure to the relation between low birth weight and subsequent hypertension.

\section{Subjects and methods}

In 1979, as part of the screening programme for the Medical Research Council's mild hypertension trial, blood pressure was measured in 6088 adults registered at the Ladywell Medical Centre in Edinburgh. In 1986, blood pressure was recorded in 864 young adults registered at the medical centre whose parents had both 
Table 1 Characteristics of offspring and parents in study population. Values are means (SD) unless stated otherwise

\begin{tabular}{|c|c|c|c|c|c|c|}
\hline & \multicolumn{2}{|c|}{ Offspring } & \multicolumn{2}{|c|}{ Fathers } & \multicolumn{2}{|c|}{ Mothers } \\
\hline & This study $(n=452)$ & $\begin{array}{c}\text { Whole study }^{7} \\
(\mathrm{n}=864)\end{array}$ & $\begin{array}{c}\text { This study } \\
(\mathrm{n}=452)\end{array}$ & $\begin{array}{c}\text { Whole study } \\
(n=603)\end{array}$ & $\begin{array}{c}\text { This study } \\
(\mathrm{n}=452)\end{array}$ & $\begin{array}{c}\text { Whole study } \\
\quad(n=603)\end{array}$ \\
\hline No of men & 231 & 458 & & & & \\
\hline Mean age (range) (years) & $21(16-26)$ & $21(16-27)$ & $45(35-64)$ & $46(35-64)$ & $43(34-62)$ & $43(34-62)$ \\
\hline Systolic blood pressure $(\mathrm{mm} \mathrm{Hg})$ & $117(13)$ & $117(13)$ & $127(17)$ & $126(18)$ & $120(18)$ & $120(18)$ \\
\hline Height (m) & $1.70(0.09)$ & $1.70(0.06)$ & & & & \\
\hline Birth weight $(\mathrm{g})$ & $3470(476)$ & & & & & \\
\hline
\end{tabular}

participated in the earlier screening programme. Some of the 864 offspring were siblings, so the cohort was drawn from 603 families. Details of these offspring and parents have been described elsewhere ${ }^{7}$ and are shown in table 1. All blood pressures were measured in the same way: at any convenient time of day, after 5 minutes of sitting, and by two trained observers using a Hawksley random zero sphygmomanometer. The means of the two readings were used for analysis. Offspring were also weighed and their height was measured, and women were asked if they were using an oral contraceptive. Offspring from this cohort were then selected from groups with maximum contrast in their predisposition to high blood pressure- that is, on the basis of offspring and parental blood pressures being in the upper or lower third of the age adjusted distribution. Subgroups of these offspring participated in a series of further studies, which are reviewed elsewhere. $^{18} 19$

\section{Collection of data on birth weight}

In 1994 all of the 603 mothers were sent letters asking them to recall the birth weight of their offspring. Replies were received from 398 mothers, providing data for 545 offspring. In addition, the case records at Ladywell Medical Centre were examined to determine the birth weights recorded by midwives. This provided birth weights for 349 offspring, 259 of whom had birth weights recalled by their mother. We validated the maternal recall of birth weights by comparing their values with the birth weights recorded by the midwives. As described in other populations, ${ }^{20}{ }^{21}$ maternal recall of birth weight was accurate $(95 \%$ confidence interval of the mean difference between birth weights recalled by mothers and recorded by midwives was $-32 \mathrm{~g}$ to $22 \mathrm{~g}$; the $95 \%$ confidence interval for an individual measurement, or prediction interval, was $-467 \mathrm{~g}$ to $462 \mathrm{~g}){ }^{22}$

In further analyses the available birth weights recorded by midwives were used for 349 offspring and maternal recalled birth weights for the other 286 offspring. This gave birth weight for 635 participants, of whom 352 were siblings and 283 single offspring of their family. To avoid bias due to correlations between siblings, one offspring was selected at random from each family. As a result, analyses were performed on data for 452 offspring. The characteristics of these offspring and their parents for whom birth weights were obtained were not different from those for whom birth weights were not obtained (table 1).

\section{Statistical analysis}

Stepwise linear regression analysis was used to identify correlates of birth weight and systolic and diastolic blood pressure in the offspring. All observed relations were stronger for systolic than diastolic blood pressure, so only systolic blood pressures were used in further analyses. Data are shown as means (SD).

\section{Results}

The blood pressure of the offspring was higher in men than women and positively correlated with current body weight (table 2). In addition, higher maternal or paternal systolic blood pressure was associated with higher systolic blood pressure in the offspring. Birth weight was lower in the offspring of younger mothers (table 3). In addition, higher maternal, but not paternal, systolic blood pressure was associated with lower birth weight in the offspring.

If parental blood pressures were ignored birth weight and subsequent systolic blood pressure were

Table 2 Correlates of systolic blood pressure in offspring by stepwise regression analysis

\begin{tabular}{|c|c|c|c|c|c|c|}
\hline \multirow[b]{2}{*}{ Variable* } & \multicolumn{3}{|c|}{ Without parental blood pressures† } & \multicolumn{3}{|c|}{ With parental blood pressuresł } \\
\hline & Slope & $r$ value & $P$ value & Slope & $r$ value & $P$ value \\
\hline \multicolumn{7}{|l|}{ Offspring } \\
\hline Sex§ & $-6.34 \mathrm{~mm} \mathrm{Hg}$ & -0.24 & $<0.0001$ & $-6.64 \mathrm{~mm} \mathrm{Hg}$ & -0.25 & $<0.0001$ \\
\hline Birth weight & $-2.24 \mathrm{~mm} \mathrm{Hg} / \mathrm{kg}$ & -0.08 & 0.06 & $-1.71 \mathrm{~mm} \mathrm{Hg} / \mathrm{kg}$ & -0.06 & 0.15 \\
\hline
\end{tabular}

Parents

Systolic blood pressure:

\begin{tabular}{lllllll}
\hline Mother & - & - & - & $0.12 \mathrm{~mm} \mathrm{Hg} / \mathrm{mm} \mathrm{Hg}$ & 0.16 & $<0.0001$ \\
\hline Father & - & - & - & $0.11 \mathrm{~mm} \mathrm{Hg} / \mathrm{mm} \mathrm{Hg}$ & 0.14 & $<0.001$ \\
\hline
\end{tabular}

*Variables that were not significant $(P>0.10)$ in either analysis were offspring's age, height, and use of contraceptive pill and maternal and paternal age and diastolic blood pressure.

†Overall, $r=0.48$ and $F=44$. $\ddagger 0$ verall, $r=0.52$ and $F=35$. $\S$ Assigned dummy values of 0 for men and 1 for women. 
Table 3 Correlates of birth weight by stepwise regression analysis

\begin{tabular}{lccc} 
Variable* $^{*}$ & Slope & $r$ value† & P value \\
\hline Mother's age at parturition & $12.7 \mathrm{~g} / \mathrm{year}$ & 0.10 & $<0.04$ \\
\hline Mother's systolic blood pressure & $-3.03 \mathrm{~g} / \mathrm{mm} \mathrm{Hg}$ & -0.12 & $<0.01$
\end{tabular}

*Variables that were not significant were paternal systolic and diastolic blood pressure, maternal diastolic blood pressure, and sex of offspring. †Overall, $r=0.14$ and $F=4.6$.

inversely correlated after correction for sex and current body weight $(\mathrm{P}=0.06)$, such that a $1 \mathrm{~kg}$ decrease in birth weight was associated with a $2.24 \mathrm{~mm} \mathrm{Hg}$ increase in systolic blood pressure (table 2). However, if parental blood pressures were included in the regression model they had a significant effect, such that the relation between birth weight and blood pressure was weaker $(\mathrm{P}=0.15)$, a $1 \mathrm{~kg}$ decrease in birth weight being associated with a $1.71 \mathrm{~mm} \mathrm{Hg}$ increase in systolic blood pressure (table 2).

\section{Discussion}

This study confirms a relation between low birth weight and high blood pressure in young adults which is of similar strength to that found in other groups of this age. ${ }^{1}$ Given the small sample size relative to other studies, this relation was not significant. The study also confirms the well documented influence of parental blood pressure on blood pressure in offspring. ${ }^{7}$ Our study allows the contribution of parental blood pressure to the relation between low birth weight and high blood pressure in adult offspring to be assessed. It shows that mothers with higher blood pressure measured between 9 and 19 years after their pregnancy had offspring with lower birth weight $(\mathrm{P}<0.01)$. These results suggest that low birth weight is, at least in part, a feature of the inherited contribution to hypertension. In this context, the inherited contribution may be mediated by genetic or shared environmental factors, or both. As a result, the correlation between low birth weight and subsequent high blood pressure is confounded by the influence of parental blood pressure.

The size of this confounding effect is difficult to measure because of differences in the precision of the measurements. Both inherited and non-inherited factors are likely to contribute to the relation between birth weight and systolic blood pressure. When we accounted for parental blood pressure, the slope of the relation was reduced from $2.24 \mathrm{~mm} \mathrm{Hg} / \mathrm{kg}$ to $1.71 \mathrm{~mm} \mathrm{Hg} / \mathrm{kg}$ (table 2), suggesting that as much as $24 \%$ is accounted for by inherited factors. However, the offspring in this study, born in Edinburgh during 1959-70, lived in a comparatively favourable economic and nutritional environment. The influence of variations in maternal nutrition during pregnancy may be comparatively small in this group, making the inherited influence more apparent. In other populations-for example, those born in India or in wartime Europe, ${ }^{23}{ }^{24}$-nutritional factors may be more important. None the less, these observations have important implications for attempts to explain the correlates of low birth weight in humans. In addition to investigation of programmed responses to events in early life, inherited mechanisms should be sought
- Hypertension has both inherited and environmental causes

- The relation between low birth weight and hypertension in later life may result from the mother's nutritional environment during pregnancy

- This study found that mothers who have higher blood pressure in later life deliver babies with lower birth weight, who also develop higher blood pressure

- Hereditary factors therefore explain part of the relation between low birth weight and adult hypertension

which could explain the association between low birth weight and high blood pressure.

\section{Contrasting influence of mother's and father's blood pressure}

Birth weight was related to maternal but not paternal blood pressure. This may be because of the influence of maternal size on birth weight ${ }^{8}$ and the putative imprinting of exclusively maternal genes ${ }^{25}$ However, a more likely explanation is that birth weight is dependent on blood pressure during pregnancy. Blood pressure during pregnancy is related to that in later life. ${ }^{26}$ Mothers with higher blood pressure seemed to deliver smaller babies only if the hypertension was severe and resulted in premature delivery. ${ }^{14}{ }^{16}$ Therefore, maternal blood pressure was thought not to contribute to the association between low birth weight and adult hypertension which occurs across the range of birth weight and is independent of gestational age. ${ }^{14}$ We were not able to obtain reliable data for gestational age in our subjects to establish whether, across the range of normal blood pressure, mothers with higher blood pressure delivered earlier. However, recent data using ambulatory blood pressure monitoring has shown that higher maternal blood pressure is associated with lower birth weight independently of gestational age. ${ }^{12}$ The current observations could be explained if mothers who have higher blood pressure in middle age also had higher blood pressure in pregnancy which was associated with lower birth weight in their offspring.

\section{Conclusion}

This study shows a link between two major areas of research in hypertension: the fetal origins and hereditary hypotheses. It will be important to establish whether other correlates of low birth weight-for example, insulin resistance-are subject to the same confounding interactions.

We thank Dr H V Edwards, Mr C J Foy, Professor S B Harrap, and Dr D W Holton for their help in developing studies in this cohort, and Dr M Upton for helpful discussion.

Contributors: BRW contributed to formulating the hypothesis and to generating funds, supervised the collection and analysis of data, and coordinated writing the paper. AMcC collated the data on birth weight and blood pressure, performed statistical analyses, and contributed to writing the paper. JPN collected and collated the birth weight data. DJW contributed to formulating the hypothesis, generating funds, supervising the 
collection of birth weight data, and writing the paper. GCMW initiated and supervised the collection of blood pressure data, contributed to formulating the hypothesis and to generating funds, supervised the statistical analyses, and contributed to writing the paper. BRW and GCMW are guarantors for the study.

Funding: Supported by a grant from the Scottish Home and Health Department. BRW is a British Heart Foundation senior research fellow.

Conflict of interest: None.

1 Law CM, Shiell AW. Is blood pressure inversely related to birth weight? The strength of evidence from a systematic review of the literature. J Hypertens 1996;14:935-41.

2 Curhan GC, Chertow GM, Willet WC, Spiegelman D, Colditz GA, Manson JE, et al. Birth weight and adult hypertension and obesity in women. Circulation 1996;94:1310-5.

3 Curhan GC, Willett WC, Rimm EB, Spiegelman D, Ascherio AL, Stampfer MJ. Birth weight and adult hypertension, diabetes mellitus, and obesity in US men. Circulation 1996;94:3246-50.

4 Barker DJP. Fetal origins of coronary heart disease. BMJ 1995;311:171-4.

5 Langley-Evans SC, Welham SJM, Sherman RC, Jackson AA. Weanling rats exposed to maternal low-protein diets during discrete periods of gestation exhibit differing severity of hypertension. Clin Sci 1996;91: 607-15.

6 Benediktsson R, Lindsay RS, Noble J, Seckl JR, Edwards CRW. Glucocorticoid exposure in utero: new model for adult hypertension. Lancet 1993;341:339-41.

7 Watt GCM, Foy CJW, Holton DW, Edwards HE. Prediction of high blood pressure in young people: the limited usefulness of parental blood pressure data. J Hypertens 1991;9:55-8.

8 Morton NE. The inheritance of human birth weight. Am J Hum Genet 1955;20:125.

9 Godfrey K, Robinson S, Barker DJP, Osmond C, Cox V. Maternal nutrition in early and late pregnancy in relation to placental and fetal growth. BMJ 1996;312:410-4

10 Whincup P, Cook D, Papacosta O, Walker M, Perry I. Maternal factors and development of cardiovascular risk: evidence from a study of blood pressure in children. J Hum Hypertens 1994;8:337-43.

11 Law CM, Barker DJP, Bull AR, Osmond C. Maternal and fetal influences on blood pressure. Arch Dis Child 1991;66:1291-5.

12 Churchill D, Perry IJ, Beevers DG. Ambulatory blood pressure in pregnancy and fetal growth. Lancet 1997;349:7-10.
13 Seidman DS, Laor A, Gale R, Stevenson DK, Mashiach S, Danon YL. Preeclampsia and offspring's blood pressure, cognitive ability and physical development at 17-years-of-age. Br J Obstet Gynaecol 1991;98:1009-14.

14 McCowan LME, Buist RG, North RA, Gamble G. Perinatal morbidity in chronic hypertension. Br J Obstet Gynaecol 1996;103:123-9.

15 Dgani J, Arad I. Measurement of systolic blood pressure in the follow-up of low birth weight infants. J Perinat Med 1992;20:365-70.

16 Himmelmann A, Svensson A, Hansson L. Relation of maternal blood pressure during pregnancy to birth weight and blood pressure in children. The hypertension in pregnancy offspring study. J Intern Med 1994;235:347-52.

17 Taittonen L, Nuutinen M, Turtinen J, Uhari M. Prenatal and postnatal factors in predicting later blood pressure among children: cardiovascular risk in young Finns. Pediatr Res 1996;40:627-32.

18 Harrap SB, Fraser R, Inglis GC, Lever AF, Beastall GH, Dominiczak MH, et al. Abnormal epinephrine release in young adults with high personal and parental blood pressures. Circulation 1997;96:556-61.

19 Noon JP, Walker BR, Webb DJ, Shore AC, Holton DW, Edwards HV, et al. Impaired microvascular dilatation and capillary rarefaction in young adults with a predisposition to high blood pressure. I Clin Invest 1997;99:1873-9.

20 Lumey LH, Stein AD, Ravelli ACJ. Maternal recall of birthweights of adult children: validation by hospital and well baby clinic records. Int J Epidemiol 1994;23:1006-12.

21 Troy LM, Michels KB, Hunter DJ, Spiegelman D, Manson JE, Colditz GA, et al. Self-reported birthweight and history of having been breastfed among younger women: an assessment of validity. Int J Epidemiol 1996;25:122-7.

22 Bland JM, Altman DG. Statistical methods for assessing agreement between two methods of clinical measurement. Lancet 1986;i:307-10.

23 Lumey LH, Stein AD, Ravelli ACJ. Timing of prenatal starvation in women and birth weight in their first and second born offspring: the Dutch famine birth cohort study. Eur J Obstet Gynecol Reprod Biol 1995;61:23-30.

24 Stein CE, Fall CHD, Kumaran K, Osmond C, Cox V, Barker DJP. Fetal growth and coronary heart disease in South India. Lancet 1996;348: 1269-73.

25 Lalande M. Parental imprinting and human disease. Annu Rev Genet 1996;30:173-95

26 Chesley LC. The remote prognostic significance of the level of blood pressure in pregnancy. Clin Exp Hypertens (A) 1980;2:777-801.

(Accepted 28 October 1997)

\section{A memorable letter \\ The ethos of drug safety monitoring}

Thirty four years ago Sir Derrick Dunlop, chairman of the Committee on Safety of Drugs, wrote a "Dear Doctor" letter which contained comments and promises that have proved to be important in drug safety monitoring in Britain.

The committee-forerunner of today's Committee on Safety of Medicines-asked "every member of the medical profession in the United Kingdom" to report "promptly details of any untoward condition in a patient which might be the result of drug treatment." The italic emphasis was Sir Derrick's and its consequence is that even today the yellow card reporting form is headed to show that it is concerned with suspected adverse drug reactions.

Do doctors realise that they are not asked to prove anything? What is needed is the suspicions of alert clinicians regarding what might be an adverse reaction to drug treatment. Today's yellow card emphasises this by asking, with regard to recently introduced products, that reports should be made on "all suspected reactions, including minor ones, that could conceivably be attributed to the drug."

The same philosophy extends throughout most forms of pharmacovigilance: the methods that are conducted on a national scale, the yellow card scheme ${ }^{1}$ and prescription event monitoring, ${ }^{2}$ are essentially hypothesis generating. The safety database for newly licensed drugs is limited, ${ }^{3}$ and the need is for widespread surveillance that will raise signals, or hypotheses, that something unsuspected may show up when the drug is used in large populations. If there are suspicions these can be confirmed or refuted in the hypothesis testing methods of pharmacoepidemiology, such as case control or cohort studies or randomised controlled clinical trials. Derrick Dunlop's "might" put the emphasis in the right place.

The letter promised that all the reports or replies that the committee received from doctors would be treated with complete professional confidence and that the information supplied would never be used for disciplinary purposes or for inquiries about prescribing costs. These undertakings have been kept even though at one stage it needed the minister of the day to issue a certificate of public interest to protect the inviolability of the adverse reaction reporting data.

To safeguard the public welfare it is essential that drug safety monitoring continues, covered by "complete professional confidence," as it has since Derrick Dunlop and his colleagues founded the yellow card scheme in 1964. Doctors should bear in mind the undertakings that have been given and are quoted above.

We have good reason to look back to the letter of 34 years ago that produced much of the ethos of drug safety monitoring today when copies of the letter itself are a rarity.

Ronald D Mann, senior professorial fellow, University of Southampton

1 Rawlins MD. Spontaneous reporting of adverse drug reactions. QJ Med 1986;59: 531-4.

2 Mann RD, Wilton LV, Pearce GL, Mackay FJ, Dunn NR. Prescription-event monitoring (PEM) in 1996-a method of non-interventional observational cohort pharmacovigilance. Pharmacoepidemiology and Drug Safety 1997;6(suppl 3):S5-S11.

3 Rawlins MD, Jefferys DB. United Kingdom product licence applications involving new active substances, 1987-1989: their fate after appeals. Br J Clin Pharmacol 1993;35:599-602.

We welcome articles up to 600 words on topics such as A memorable patient, A paper that changed my practice, My most unfortunate mistake, or any other piece conveying instruction, pathos, or humour. If possible the article should be supplied on a disk. Permission is needed from the patient or a relative if an identifiable patient is referred to. 